\title{
Model Bisnis Ekowisata di Taman Nasional Laut Bunaken dengan Pendekatan Business Model Canvas
}

\author{
Business Model of Ecotourism at Bunaken National Marine Park \\ with the Business Model Canvas Approach
}

\author{
Mawardi Bagindo $^{1^{*}}$, Bunasor Sanim², dan Imam Teguh Saptono ${ }^{3}$ \\ ${ }^{1}$ Mahasiswa Program Manajemen dan Bisnis IPB; Jl. Masjid Al Barokah No.8 Ciherang, Dramaga, Kab. Bogor 16680; \\ ${ }^{2}$ Program Manajemen dan Bisnis IPB, Jl. Raya Pajajaran, Bogor 16151; email: bunasor@indo.net.id; 0811110415 \\ ${ }^{3}$ Program Pascasarjana Manajemen dan Bisnis IPB, Jl. Raya Pajajaran, Bogor 16151; \\ email: isaptono@yahoo.co.id; 08561040701
}

\begin{abstract}
ABSTRAK
Peran sektor pariwisata semakin penting seiring dengan perkembangan struktur ekonomi Indonesia yang mengarah ke sektor jasa. Pendekatan model bisnis adalah salah satu faktor penting untuk keberhasilan suatu organisasi. Taman Nasional Laut Bunaken di Sulawesi Utara merupakan perwakilan dari ekosistem air tropis di Indonesia yang terdiri dari mangrove, padang lamun, terumbu karang dan pesisir . Tujuan penelitian ini untuk mengidentifikasi model bisnis Bunaken dan menganalisis perbaikan dengan metode deskriptif kualitatif. Metode pemodelan bisnis dianalisis dengan sembilan unsure dari business model canvas. Peningkatan value proposition, segmen pelanggan, dan hubungan pelanggan akan mempengaruhi pendapatan suatu organisasi. Value proposition membutuhkan key activities, key resources dan key partnership. Pengelolaan Bunaken harus memiliki sumber daya manusia yang tepat untuk menerapkan model ini.
\end{abstract}

Kata kunci: Bunaken, business model canvas, ekowisata, model bisnis

\begin{abstract}
The role of tourism sector increasingly important in line with the development of Indonesian economic structure leading to services sector. Business modelling approach is one of the critical factor to the success of an organization. Bunaken National Marine Park in North Celebes is a representative of the tropical water ecosystem in Indonesia that consists of mangrove, seagrass, coral reefs and coastal. The objective of this research were to identify the business modelling of Bunaken and to analyze its improvements using descriptive-qualitative method. Business modelling method were analyzed by business model canvas 9 building block. Increasing of the value proposition, costumer segment, costumer relationship would be affected to revenue stream organization. Supporting the value proposition needed key activities, key resources and key partnership. The management of Bunaken should have the appropriate human resources to apply this modelling.
\end{abstract}

Key words: Bunaken, business model, business model canvas, ecotourism

\section{PENDAHULUAN}

Indonesia dikenal sebagai negara kepulauan yang terdiri dari daratan dan lautan seluas \pm 5,8 juta $\mathrm{Km}^{2}$ dan sekitar $70 \%$ wilayahnya merupakan perairan laut dengan garis pantai sepanjang $\pm 81.000 \mathrm{Km}$. Salah satu kekayaan keanekaragaman hayati yang ada di Indonesia adalah ekosistem terumbu karang. Terumbu karang merupakan salah satu bagian dari ekosistem pesisir yang mempunyai manfaat yang sangat banyak. Pengembangan potensi wisata bahari memiliki arti strategis dalam pengembangan budaya bahari, usaha multisektor, ekonomi daerah, dan penguatan peran serta masyarakat.

\footnotetext{
*) Korespondensi:

Jl. Masjid Al Barokah No.8 Ciherang, Dramaga, Kab. Bogor 16680; email: mawardi.bagindo@gmail.com; 085216589177
} 
Peran sektor pariwisata semakin penting sejalan dengan perkembangan struktur perekonomian Indonesia yang makin mengarah ke sektor jasa. Menurut Kemenpar, sepanjang periode 20052012, pariwisata kawasan ini mampu tumbuh rataan $8,3 \%$ per tahun, jauh di atas rataan pertumbuhan global yang hanya 3,6\%. Perkembangan itu membuat peran sektor pariwisata semakin penting bagi perekonomian negaranegara ASEAN. Pada 2023, potensi kontribusi pariwisata terhadap perekonomian kawasan ini diproyeksikan akan mencapai US\$ 480 miliar dengan pertumbuhan rataan $5,8 \%$ per tahun, sedangkan pertumbuhan investasinya $6,8 \%$ per tahun.

Taman Nasional merupakan kawasan ekosistem asli yang dikelola dengan sistem zonasi untuk tujuan penelitian, ilmu pengetahuan, pendidikan, pariwisata, dan rekreasi. Penetapannya memperhatikan berbagai kriteria dalam UU No.5 tahun 1990 tentang Konservasi Sumber Daya Alam Hayati dan Ekosistem. Kawasan Taman Nasional terdiri dari beberapa zona yaitu zona inti, zona rimba, zona perlindungan bahari untuk wilayah perairan, zona rimba, zona pemanfaatan, dan zona khusus seperti zona tradisional, zona rehabilitas dan zona religi (Permenhut No. 56/ 2006, PP No.28/2011, UU 41/99).

Salah satu ekowisata bahari yang sedang berkembang saat ini adalah Taman Nasional Laut (TNL) Bunaken. Tempat wisata ini merupakan perwakilan ekosistem perairan tropis Indonesia yang terdiri dari ekosistem hutan bakau, padang lamun, terumbu karang, dan ekosistem daratan/ pesisir. Taman laut ditunjuk sebagai Taman Nasional berdasarkan SK Menteri Kehutanan No.730/Kpts-II/1991 yang dikelola melalui sistem zonasi.

Ekowisata terus mengalami pengembangan yang cukup pesat. Menurut Iskandarsyah (2013), ekowisata didefinisikan sebagai bentuk kegiatan pariwisata yang memanfaatkan keaslian lingkungan alam, terjadi interaksi antara lingkungan alam dan aktivitas rekreasi, konservasi, dan pengembangan. Namun pengertian istilah ekowisata terus mengalami perkembangan seiring dengan kondisi lingkungan yang kian dinamis. Kegiatan ekowisata tidak hanya sebatas aktivitas rekreasi namun disertai bentuk tanggungjawab terhadap kelestarian area yang masih alami, memberikan manfaat secara ekonomi, dan mempertahankan budaya bagi masyarakat sekitar (Mulyadi et al. 2008).
Menurut Singh (2006), pengembangan ekowisata berkelanjutan (sustainability of ecotourism) dipengaruhi oleh beberapa aspek seperti tingkat kebiasaan dan sikap masyarakat terhadap lingkungannya, tingkat dukungan kebijakan pemerintah dalam pengembangan ekowisata, pengetahuan tentang konservasi lingkungan itu sendiri, serta tanggungjawab para pihak yang terkait (stakeholders).

Saat ini model pengelolaan yang ada di Indonesia adalah pengelolaan berbasis ekosistem, spesies, pemberdayaan masyarakat maupun penetapan Taman Nasional. Model belum mampu mengatasi masalah secara optimal. Pemerintah harus berperan aktif dan strategis dalam mengambil kebijakan pengembangan obyek wisata alam. Ketidakmampuan organisasi untuk mengantisipasi perubahan secara tepat umumnya dikarenakan organisasi tidak mengetahui kekurangannya dan tidak mengetahui kondisi lingkungannya.

Manajemen strategik merupakan serangkaian kebijakan dan tindakan manajerial yang menentukan kinerja perusahaan dalam jangka panjang, terdiri atas pengamatan lingkungan, perumusan strategi, implementasi strategi, dan evaluasi serta pengendalian (Wheelen dan Hunger, 2010). Dalam manajemen strategik terdapat dua masalah utama. Masalah yang pertama adalah kemampuan suatu perusahaan dalam mengidentifikasi pola unik dari tantangan, kendala, dan peluang masa depan. Masalah yang kedua adalah bagaimana merancang dan mengimplementasikan perubahan yang unik atas tantangan yang dihadapi suatu perusahaan (Ansoff dan McDonnel, 1990). Manajemen strategik mengintegrasikan semua level organisasi dari proses manajemen yang berkelanjutan dalam perumusan, implementasi, dan evaluasi masa depan organisasi (Marin, 2012). Menurut Tripomo dan Udan (2005), manajemen strategik bertujuan mengimplementasikan suatu strategi dalam organisasi melalui tahapan perumusan, implementtasi, evaluasi, pengendalian dan perbaikan strategi.

Salah satu pendekatan dalam membuat suatu pengembangan adalah dengan menggunakan pendekatan model bisnis. Faktor pengembangan model bisnis tidak hanya dari teknologi, tetapi juga dari faktor ekonomi seperti mencari penciptaan nilai pemegang saham dan juga faktor regulasi, terutama deregulasi sektor telekomunikasi yang memiliki pengaruh nyata dan menyebabkan munculnya bisnis baru, model pendapatan, dan kompleksitas hubungan antar- 
perusahaan (Sahut et al. 2013). Konsep model bisnis kemudian dibangun melalui penambahan dan penyempurnaan dari berbagai artikel, laporan dan buku yang ada untuk memperjelas makna dari waktu ke waktu (Lecocq et al. 2010).

Pendekatan model bisnis salah satu faktor kritis untuk sukses dari suatu organisasi. Pendekatan model bisnis ini cukup banyak macamnya, salah satunya adalah Business Model Canvas (BMC) yang dikembangkan oleh (Ostewalder dan Pigneur 2013). Pendekatan model bisnis ini harus inovatif agar suatu organisasi mampu bertahan ditengah perkembangan zaman sangat dinamis (Giesen et al. 2010). BMC terdiri dari Sembilan unsur yang digunakan untuk membantu memetakan model bisnis suatu organisasi yang dianalisis menjadi model bisnis yang lebih baik bagi pengembangan kawasan TNL Bunaken.

Sektor pariwisata mampu menarik wisatawan nusantara maupun mancanegara dan ini menjadi daya tarik bagi masyarakat TNL Bunaken sebagai mata pencaharian. Adanya potensi sumber daya di TNL Bunaken belum dimanfaatkan secara optimal. Dalam pengelolaannya menunjukkan manajemen strategik pengembangan TNL Bunaken belum efektif dalam mengatasi permasalahan maupun konflik yang ada di dalam kawasan. Dari latar belakang tersebut, dapat dirumuskan permasalahnya adalah (1) Bagaimana model bisnis yang ada di TNL Bunaken saat ini, ditinjau melalui pendekatan business model canvas?; (2) Bagaimana perbaikan dari model bisnis yang lama, dibuat melalui pendekatan business model canvas?

Tujuan dari penelitian ini adalah (1) Mengidentifikasi model bisnis di TNL Bunaken dengan pendekatan business model canvas; dan (2) Membuat model bisnis yang baru melalui pendekatan business model canvas.

\section{METODE PENELITIAN}

Penelitian ini dilakukan di Taman Nasional Bunaken, Kota Manado, Sulawesi Utara. Pengambilan data primer dan data sekunder dilakukan pada bulan Agustus hingga September 2014.

Metode yang digunakan dalam penelitian ini adalah metode deskriptif-kualitatif. Tujuan dari metode ini bersifat suatu paparan pada peubah yang akan diteliti, misalnya tentang siapa, yang mana, kapan dan dimana. Penelitian dengan metode studi kasus menghendaki suatu kajian yang rinci, mendalam dan menyeluruh atas obyek tertentu yang biasanya relatif kecil dalam kurun waktu tertentu, termasuk lingkungannya (Umar 2010). Metode kualitatif utama yang digunakan adalah sembilan unsure business model canvas yang diadopsi dari 9 blocks building of Business Model Canvas (Osterwalder dan Pigneur, 2013).

\section{Jenis dan Sumber Data}

Data primer meliputi informasi, pendapat, kebijakan dan pertimbangan yang berasal dari pihak pengelola TNL Bunaken, pemerintah daerah, LSM/Swasta, tokoh masyarakat dan mitra. Informasi tersebut terkait dengan permasalahan yang dihadapi, kegiatan yang dilakukan, kondisi sumberdaya yang dimiliki, serta peluang dan ancaman yang dihadapi organisasi. Data sekunder diperoleh dari berbagai sumber melalui studi pustaka instansi dan literatur internet.

Data primer diperoleh peneliti dari responden yang dipilih secara sengaja (purposive sampling). Kriteria dalam penetapan pakar adalah seseorang yang sudah lama menekuni bidangnya, serta ahli di bidang konservasi dan kelautan.

\section{Pengumpulan Data dan Informasi}

Pengumpulan data bertujuan untuk memperoleh informasi, gambaran dan keterangan tentang hal-hal yang berkaitan dengan materi penelitian sehingga data tersebut dapat digunakan menganalisis setiap aspek yang dikaji. Data yang berhubungan dengan aspek teoritis diperoleh melalui penelitian kepustakaan antara lain jurnal, tesis, disertasi, buku teks, majalah, internet dan pustaka lainnya yang relevan dengan penelitian ini. Data primer diperoleh dengan wawancara, kuesioner, observasi dan studi dokumentasi digunakan untuk memperoleh sejumlah data dan informan di lapangan berupa dokumen administratif untuk melengkapi data penelitian ini.

Teknik pengambilan contoh dalam penelitian ini menggunakan pengambilan contoh tanpa peluang (non probability), yaitu pengambilan contoh secara sengaja (purposive sampling). Dengan teknik ini responden sudah ditentukan peneliti atas dasar pertimbangan bahwa semua responden dianggap memiliki kompetensi dan kapasitas untuk memberikan masukan terhadap perancangan Business Model Canvas.

\section{Pengolahan dan Analisis Data}

Pengolahan dan analisis data pada penelitian ini meliputi analisis deskriptif, pemetaan model bisnis existing, identifikasi faktor-faktor 
internal dan eksternal, analisis SWOT. Analisis SWOT didasarkan pada asumsi bahwa strategi efektif diturunkan dari "kesesuaian" yang baik antara sumberdaya yang dimiliki perusahaan (kekuatan dan kelemahan) dengan situasi eksternalnya (peluang dan ancaman). Kesesuaian yang baik akan memaksimalkan kekuatan dan peluang perusahaan serta meminimalkan kelemahan dan ancaman (Pearce dan Robinson, 2008). Kemudian perancangan model bisnis baru dalam bentuk Business Model Canvas.

\section{HASIL DAN PEMBAHASAN}

TNL Bunaken adalah sebuah kawasan konservasi yang kaya dengan segala potensi jenis dan ekosistemnya merupakan anugerah Tuhan yang perlu disyukuri dan dikelola secara arif, bijaksana, dan terkoordinasi agar pemanfaatannya dapat dilakukan secara optimal dengan tetap memperhatikan aspek kelestariannya dan dapat menunjang tingkat kesejahteraan masyarakat. TNL Bunaken ditunjuk sebagai kawasan pelestarian alam melalui Surat Keputusan Menteri Kehutanan Nomor 730/Kpts-II/1991 tanggal 15 Oktober 1991 dengan luas 89.065 ha, yang terdiri atas empat wilayah administrative, yaitu Kota Manado, Kab. Minahasa, Kab. Minahasa Utara, dan Kab. Minahasa Selatan. TNL Bunaken meliputi P. Bunaken, P. Manado Tua, P. Mantehage, P. Siladen, P. Nain, pesisir MolasWori, dan pesisir Arakan-Wawontulap.

TNL Bunaken merupakan salah satu kawasan pelestarian alam, berbasis perairan yang memiliki tiga fungsi utama, yaitu pelestarian keanekaragaman hayati pesisir dan laut, mendukung kehidupan dan penghidupan masyarakat setempat, serta pengembangan pariwisata alam. Ketiga fungsi tersebut menjadi sangat penting dipertimbangkan dalam bentuk pengelolaan yang bersifat dinamis dan efektif tetapi efisien. Zonasi menjadi salah satu dasar pengelolaan TNL Bunaken. TNL Bunaken memiliki tujuan utama, yaitu:

1. Perlindungan sumber daya dan ekosistem terumbu karang, lamun, mangrove, serta flora dan fauna terrestrial dalam kawasan TNL Bunaken untuk pelestarian keanekaragaman hayati.

2. Pemanfaatan potensi sumber daya alam (SDA) untuk kesejahteraan masyarakat, penelitian, pendidikan, pengembangan budaya, pariwisata alam dan rekreasi.
Proses identifikasi unsur model bisnis ini melibatkan pihak-pihak terkait dalam pengelolaan TNL Bunaken. Tahap ini merupakan tahap awal untuk memotret kondisi model bisnis TNL Bunaken melalui pendekatan BMC. Konsep model bisnis menawarkan cara yang koheren bagi manajer untuk mempertimbangkan pilihannya dalam lingkungan yang tidak pasti dan bergerak cepat (McGrath, 2010).

Pada dasarnya semua perusahaan memiliki model bisnis, namun belum tentu sesuai dengan lanskap bisnis perusahaan. Untuk itu diperlukan model bisnis yang tepat dalam menjalankan bisnisnya (Tjaturpriono, 2010). Kondisi model bisnis TNL Bunaken saat ini disajikan pada Gambar 1.

\section{Customer Segments}

Berdasarkan hasil observasi, pengisian kuesioner dan wawancara di TNL Bunaken, terdapat dua kategori customer segment yaitu wisatawan lokal dan wisatawan asing. Wisatawan lokal biasanya lebih suka berwisata dalam jumlah banyak (rombongan), serta lebih mementingkan kebersamaan dibandingkan pengalaman.

\section{Value Proposition}

Dari hasil wawancara dan observasi, value proposition yang ditawarkan di TNL Bunaken berupa keindahan panorama bawah laut yang memberikan pengalaman menarik bagi setiap wisatawan yang berkunjung, serta jarak relatif dekat dengan pusat Kota Manado. TNL Bunaken secara geografis terletak di pusat segitiga terumbu karang (Coral Triangle), maka wajar jika kawasan ini menjadi primadona wisatawan, terutama para penyelam yang umumnya berasal dari mancanegara. Kegiatan pariwisata utama adalah penyelaman (diving). Namun dapat juga dijadikan sebagai tempat obyek penelitian dan penambahan pengetahuan mengenai keanegaraman jenis flora dan fauna yang ada di TNL Bunaken.

\section{Channels}

Untuk mencapai pelanggan, pihak pengelola TNL Bunaken melakukan kerjasama dengan asosiasi pihak asing seperti NSWA (North Sulawesi Watersports Association) untuk memasarkan TNL Bunaken baik di dalam maupun luar negeri. Selain itu, pihak pengelola menggunakan saluran distribusi melalui internet, festival budaya, pameran di berbagai event nasional maupun internasional. Pihak pengelola juga bermitra dengan para pemilik usaha seperti agen travel, 
perhotelan, masyarakat di kawasan TNL Bunaken, maupun guide lokal sebagai saluran distribusi tidak langsung.

\section{Customer Relationship}

Pada dasarnya customer relationship merupakan cara organisasi berkomunikasi untuk mempertahankan pelanggan lama dan mendapatkan pelanggan baru. Customer relationship menjadi faktor penting bagi keberlangsungan organisasi. Berdasarkan hasil observasi, pengisian kuesioner, dan wawancara, pihak TNL Bunaken membangun customer relationship tidak secara individual, namun secara kelompok (communities). Misalnya dengan komunitas penyelam (diving), dan Asosiasi Angkutan Laut yang secara tidak langsung membangun relasi dan kenyamanan bagi pelanggan melalui jasa yang ditawarkan.

\section{Revenue Stream}

Berdasarkan observasi, pengisian kuesioner dan wawancara yang telah dilaksanakan, di TNL Bunaken memiliki beberapa jenis revenue stream berupa dana APBN dan APBD, tarif masuk kawasan, dan donasi. Hal ini menjadi sumber pemasukan utama dari TNL Bunaken yang digunakan untuk membangun dan membiayai kegiatan operasional.

\section{Key Resources}

Berdasarkan hasil observasi, pengisian kuesioner dan wawancara, maka TNL Bunaken memiliki key resources berupa SDA (fasilitas/fisik) dan sumber daya manusia (SDM). SDM yang berkompeten dapat menjadi faktor penting dari kinerja suatu organisasi, bahkan mungkin peran SDM dan kompetensi memiliki proporsi yang lebih besar dari nilai-nilai perusahaan (Nielsen dan Montemari, 2012).

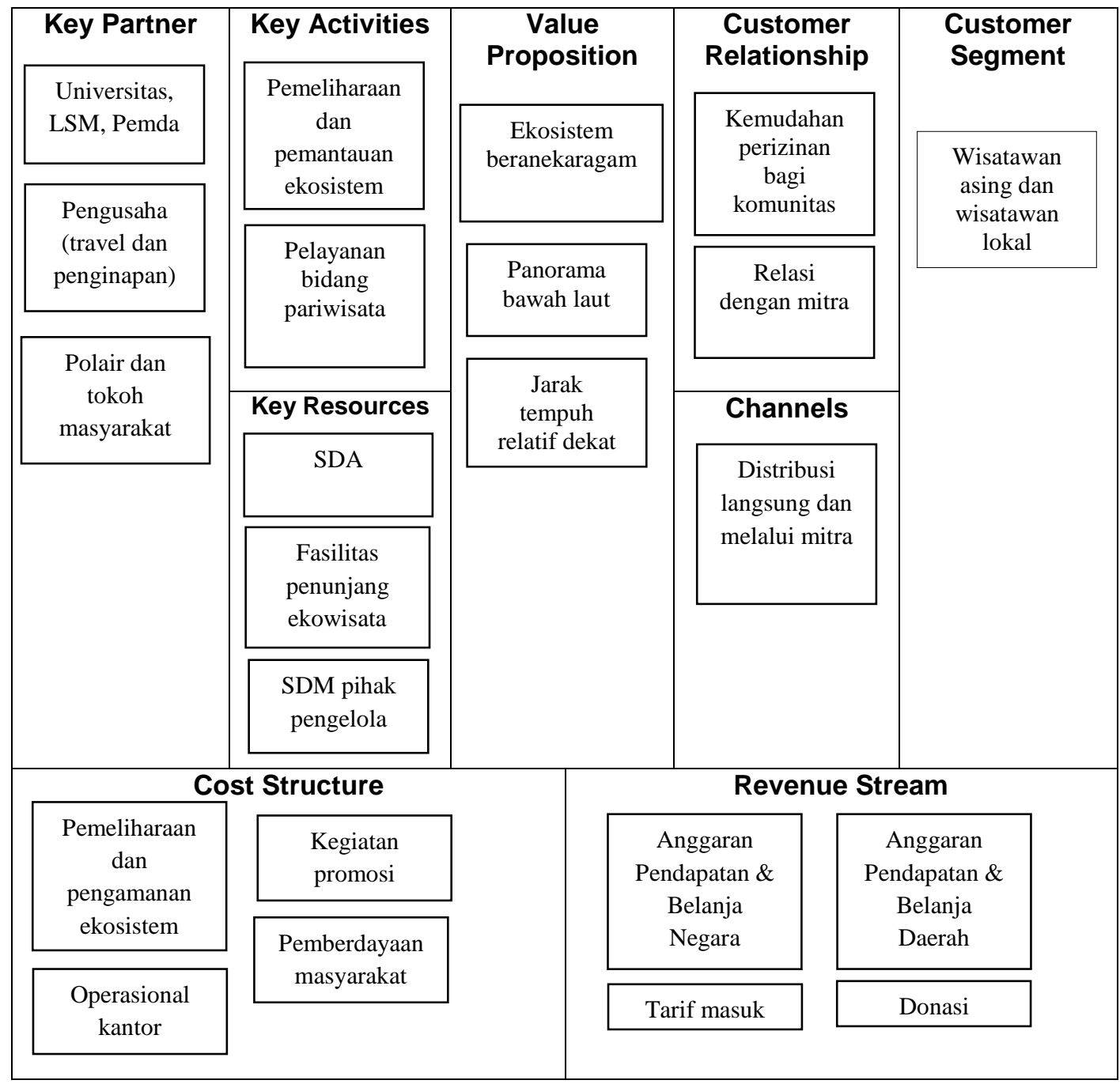

Gambar 1. Business model canvas di TNL Bunaken saat ini 


\section{Key Activities}

Secara umum Key Activities di kawasan TNL Bunaken yang bergerak di bidang pariwisata adalah operasi jasa (pelayanan). Kegiatan utama yang dilakukan adalah pelayanan bagi para wisatawan, baik mulai dari para wisatawan mencari informasi mengenai TNL Bunaken, hingga pemeliharaan dan pemantauan kelestarian alam di kawasan.

\section{Key Partnerships}

Pihak pengelola TNL Bunaken memiliki beberapa mitra untuk menunjang kegiatan bisnisnya. Key activity yang perlu dilakukan di TNL Bunaken adalah kegiatan operasi jasa atau pelayanan. Sebagai organisasi yang bergerak di bidang pariwisata, pelayanan merupakan aktivitas kunci dan untuk melayani para wisatawan, dibutuhkan suatu mitra yang dapat diajak untuk bekerjasama antara lain Universitas, pemda, pengusaha, polair dan tokoh masyarakat setempat. Kemitraan ini berperan penting dalam menjaga kelestarian alam kawasan TNL Bunaken.

\section{Cost Structure}

Pihak pengelola TNL Bunaken memiliki beberapa bagian penting dalam pembiayaannya yang berkaitan dengan key activities, key resources dan key partnership. Berdasarkan observasi, pengisian kuesioner dan wawancara maka cost structure yang telah diidentifikasi meliputi biaya pemeliharaan fasilitas, biaya pengawasan dan pemeliharaan ekosistem, gaji SDM, biaya promosi, serta pemberdayaan masyarakat.

\section{Analisis SWOT}

Setelah mengidentifikasi unsur BMC di TNL Bunaken saat ini, maka tahap selanjutnya adalah melakukan analisis SWOT pada setiap unsur BMC saat ini. Hasil dari analisis SWOT ini dapat digunakan untuk menyempurnakan business model yang telah diterapkan, sehingga bisnis akan semakin berkembang (Gambar 1).

Analisis SWOT merupakan analisis tentang kekuatan sebagai keunggulan yang dimiliki organisasi, kelemahan yang terdapat dalam organisasi, peluang bagi organisasi untuk berkembang dan ancaman yang menjadi tantangan dan hambatan yang perlu diatasi oleh organisasi. Berdasarkan hasil observasi, pengisian kuesioner dan wawancara, hasil analisis SWOT dimuat pada Tabel 1.
Channels. Koordinasi antar agen travel perlu untuk dilakukan, karena agen travel yang ada terkadang kurang melakukan komunikasi dalam membawa wisatawan. Selain itu kegiatan promosi harus memanfaatkan teknologi informasi yang kian pesat .Selama ini pihak pengelola belum optimal menggunakan media internet maupun jejaring sosial.

Customer Relationship. Pihak pengelola harus lebih aktif dalam menjaring wisatawan yang lebih banyak dengan memanfaatkan teknologi informasi. Penggunaan media sosial maupun website interaktif sangat bermanfaat dalam menekan biaya promosi. Hal ini diharapkan lebih efektif memudahkan wisatawan untuk berinteraksi langsung dengan pihak pengelola dalam mendapatkan informasi wisata TNL Bunaken.

Revenue Stream. Perbaikan yang dapat dilakukan di blok ini adalah lebih mengoptimal-kan penggunaan tarif masuk kawasan dengan memperhatikan segmen pelanggan. Misalnya untuk segmen wisatawan asing dikenakan tarif yang lebih mahal karena wisatawan asing sebagian besar berasal dari negara dengan pendapatan per kapita lebih tinggi dari Indonesia. Maka dari itu, kenyamanan dan ketersediaan sarana prasarana yang memadai di tempat wisata perlu diperhatikan oleh pihak pengelola. Dalam hal ini, pihak pengelola dapat menambahkan kerjasama dengan perusahaan untuk memperoleh ruang iklan, serta pengelolaan dana abadi (endowment fund) sebagai upaya untuk menjaga kestabilan finansial berkesinambungan yang bertujuan jangka panjang mengantisipasi suatu kondisi krisis seperti bencana alam, pelestarian alam, konservasi dan sebagainya.

Key Resources. SDM yang tersedia diberi materi pelatihan mengenai penggunaan TI, baik pengelolaan website, jejaring sosial, maupun penggunaan software GIS (Geographic Information System) yang bermanfaat untuk pengawasan dan pengembangan ekosistem di kawasan TNL Bunaken.

Key Partnership. Pihak pengelola harus mampu menarik investor asing maupun domestik untuk menanamkan modalnya agar terjadi perputaran ekonomi yang lebih baik. Secara tidak langsung para investor akan mempromosikan usahanya ke luar negeri dan juga akan berdampak positif bagi pengusaha lokal. 
Tabel 1. Hasil Analisis SWOT berdasarkan sembilan unsur blok business model canvas

\begin{tabular}{|c|c|c|c|c|c|}
\hline No & Aspek & Kekuatan & Kelemahan & Peluang & Ancaman \\
\hline 1 & $\begin{array}{l}\text { Customer } \\
\text { Segments }\end{array}$ & $\begin{array}{l}\text { Segmen Wisatawan } \\
\text { yang berbeda }\end{array}$ & $\begin{array}{l}\text { Pihak pengelola } \\
\text { masih menganggap } \\
\text { sama setiap segment }\end{array}$ & $\begin{array}{l}\text { Kunjungan wisatawan } \\
\text { yang terus meningkan } \\
\text { dari berbagai segmen }\end{array}$ & $\begin{array}{l}\text { Terdapat pesaing } \\
\text { dengan segmen } \\
\text { yang sama }\end{array}$ \\
\hline 2 & $\begin{array}{l}\text { Value } \\
\text { Propositions }\end{array}$ & $\begin{array}{l}\text { Potensi wisata, murah, } \\
\text { akses mudah }\end{array}$ & $\begin{array}{l}\text { Sampah, fasilitas } \\
\text { umum masih kurang }\end{array}$ & $\begin{array}{l}\text { Potensi wisata alam } \\
\text { belum dikembangkan }\end{array}$ & $\begin{array}{l}\text { Pesaing yang } \\
\text { semakin banyak }\end{array}$ \\
\hline 3 & Channels & $\begin{array}{l}\text { Memiliki kerjasama } \\
\text { agen travel, resort dan } \\
\text { asosiasi. }\end{array}$ & $\begin{array}{l}\text { Media promosi } \\
\text { seperti jejaring sosial } \\
\text { masih belum } \\
\text { dikembangkan }\end{array}$ & $\begin{array}{l}\text { Pemanfaatan } \\
\text { kemajuan teknologi } \\
\text { informasi (TI) }\end{array}$ & $\begin{array}{l}\text { Terdapat banyak } \\
\text { pesaing }\end{array}$ \\
\hline 4 & $\begin{array}{l}\text { Customer } \\
\text { Relationship }\end{array}$ & $\begin{array}{l}\text { Komunitas penyelam } \\
\text { yang terus bertambah }\end{array}$ & $\begin{array}{l}\text { Pendataan } \\
\text { wisatawan yang } \\
\text { berkunjung masih } \\
\text { belum tersedia }\end{array}$ & $\begin{array}{l}\text { Pemanfaatan } \\
\text { kemajuan TI }\end{array}$ & $\begin{array}{l}\text { Pihak pengelola } \\
\text { masih cenderung } \\
\text { pasif dalam men- } \\
\text { jaring wisatwan }\end{array}$ \\
\hline 5 & $\begin{array}{l}\text { Revenue } \\
\text { Streams }\end{array}$ & $\begin{array}{l}\text { Sumber pendapatan } \\
\text { bervariasi }\end{array}$ & $\begin{array}{l}\text { Birokrasi pihak } \\
\text { pengelola yang } \\
\text { terkait }\end{array}$ & $\begin{array}{l}\text { Penambahan sumber } \\
\text { pendapatan dari tarif } \\
\text { masuk kawasan }\end{array}$ & $\begin{array}{l}\text { Pemasukan melalui } \\
\text { APBN tidak } \\
\text { menentu }\end{array}$ \\
\hline 6 & Key Resources & $\begin{array}{l}\text { Keanekaragaman } \\
\text { potensi SDA }\end{array}$ & $\begin{array}{l}\text { SDM kompeten } \\
\text { masih kurang }\end{array}$ & $\begin{array}{l}\text { Pemanfaatan kema- } \\
\text { juan teknologi } \\
\text { informasi }\end{array}$ & $\begin{array}{l}\text { Illegal fishing, keru- } \\
\text { sakan ekosistem }\end{array}$ \\
\hline 7 & Key Activities & $\begin{array}{l}\text { Pemeliharaan dan } \\
\text { pengawasan ekosistem }\end{array}$ & $\begin{array}{l}\text { Biaya operasional } \\
\text { dan promosi tinggi }\end{array}$ & Wisata edukasi & $\begin{array}{l}\text { Biaya operasional } \\
\text { akan semakin tinggi }\end{array}$ \\
\hline 8 & $\begin{array}{l}\text { Key } \\
\text { Partnership }\end{array}$ & $\begin{array}{l}\text { Kemitraan dengan } \\
\text { berbagai instansi } \\
\text { pemerintahan dan } \\
\text { masyarakat. }\end{array}$ & $\begin{array}{l}\text { Belum ada } \\
\text { kemitraan dengan } \\
\text { lembaga keuangan } \\
\text { resmi }\end{array}$ & $\begin{array}{l}\text { Kerjasama dengan } \\
\text { pihak perbankan } \\
\text { maupun Event } \\
\text { Organizer }\end{array}$ & $\begin{array}{l}\text { Tumpah tindih } \\
\text { kepentingan }\end{array}$ \\
\hline 9 & $\begin{array}{l}\text { Cost } \\
\text { Structure }\end{array}$ & $\begin{array}{l}\text { Dana yang masuk } \\
\text { relatif terpenuhi }\end{array}$ & $\begin{array}{l}\text { Biaya operasional } \\
\text { tinggi }\end{array}$ & $\begin{array}{l}\text { Penggunaan TI untuk } \\
\text { menekan biaya } \\
\text { promosi }\end{array}$ & $\begin{array}{l}\text { Pembiayaan } \\
\text { semakin meningkat } \\
\text { di masa mendatang }\end{array}$ \\
\hline
\end{tabular}

\section{KESIMPULAN}

Berdasarkan hasil penelitian teridentifikasi unsur-unsur model bisnis di TNL Bunaken diperoleh customer segment yang ada adalah wisatawan domestik dan wisatawan asing. Value proposition yang ditawarkan berupa wisata alam bawah laut yang menarik. Customer relationship yang ada saat ini, yaitu hubungan langsung tidak hanya secara individu, namun juga dengan kelompok/komunitas penyelam dan asosiasi angkutan laut. Pendapatan yang diterima dari APBN, tarif masuk kawasan. Key resource dalam ekowisata ini adalah taman bawah laut berupa terumbu karang dan ekosistemnya, serta sumber daya manusia. Key activities yang ada adalah kegiatan pelayanan di ekowisata, kegiatan pemeliharaan dan pengawasan ekosistem kawasan TNL Bunaken. Key partnership yang dilakukan saat ini adalah dewan pengelola TNL Bunaken, instansi pemerintah, dan masyarakat setempat.
Cost structure utama adalah biaya untuk gaji SDM tetap, biaya pemeliharaan kawasan dan biaya promosi.

Perbaikan model bisnis yang menjadi perhatian pada Customer Segment adalah penambahan segmen pelajar dan perusahaan. Untuk Value Propositions dapat ditambahkan ataupun diperbaiki adalah fasilitas umum, yakni mushola, gazebo, toilet, dan ketersediaan air bersih. Untuk Customer Relationship perbaikan yang dilakukan optimasi teknologi informasi. Channels diperbaiki dengan melakukan kerjasama dengan agen travel dari luar negeri. Revenue Streams dapat menambah pemasukan dari ruang iklan dan endowment fund. Untuk Key Resources dibuat pelatihan SDM, dan untuk Key Partner bekerjasama dengan investor asing dan domestik. Cost Structure yang lebih efisien dengan pelatihan SDM dan penggunaan TI. 


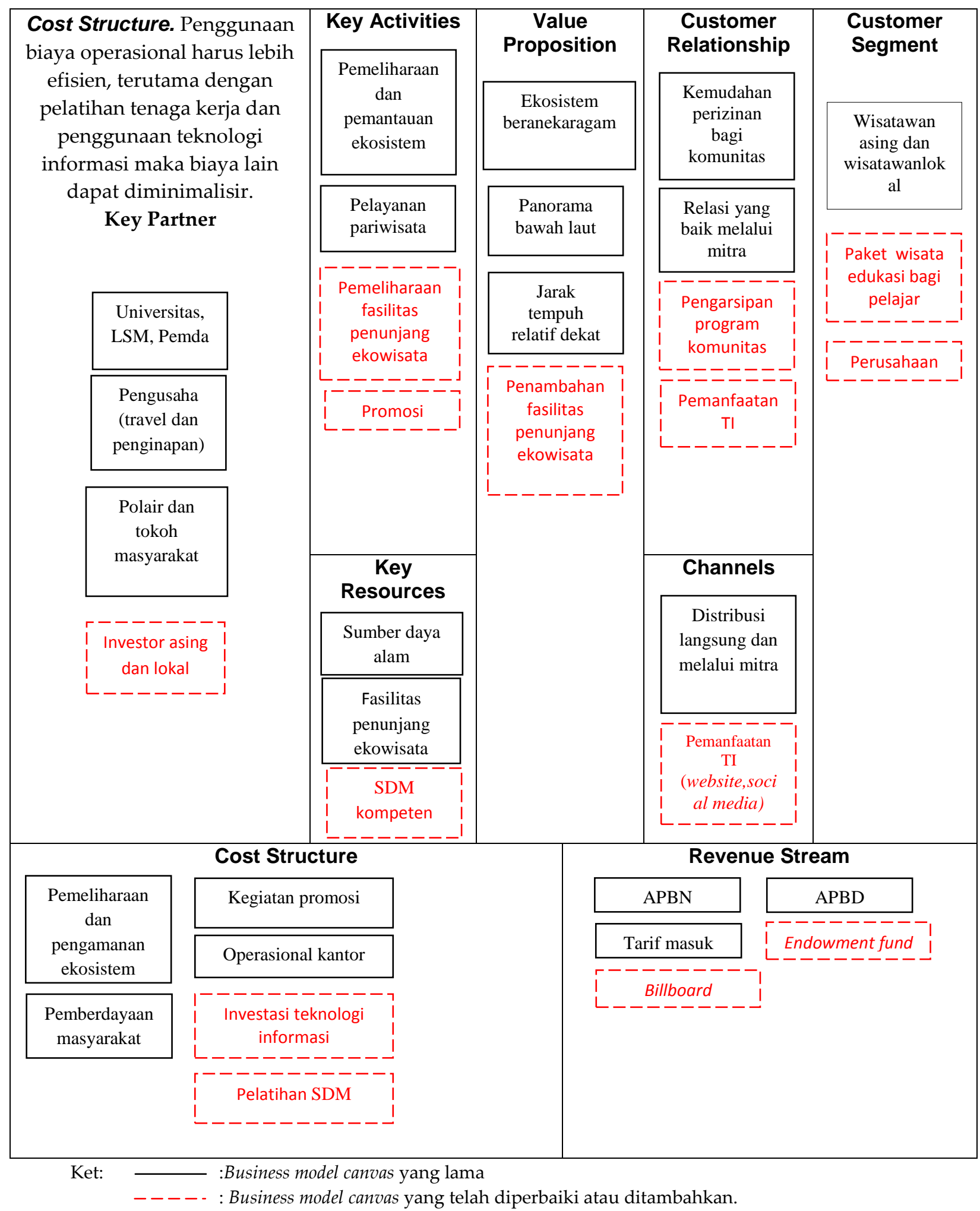

Gambar 2. Business model canvas TNL Bunaken yang telah diperbaiki

\section{DAFTAR PUSTAKA}

Amit R, Zott C. 2012. Creating value through business model innovation. J MIT Sloan Management Review, 53(3): 41-49.

Ansoff, I. dan E. Mcdonnel. 1990. Implanting Strategic Management. 2nd Ed. New York: Prentice Hall.
Aspara, Lamberg, Laukia, Tikkanen. 2011. Strategic management of business model transformation: lessons from Nokia. I Management Decision, 49(4): 622-647.

Giesen, E., E. Riddleberger, R. Christner, dan R. Bell. 2010. When and how to innovate your business model. Journal Strategy and Leadership, 38(4): 17-26. 
Iskandarsyah, M. 2013. Analisis Model Bisnis Ekowisata di Pulau Pramuka, Kepulauan Seribu dengan Pendekatan Business Model Canvas [tesis]. Bogor (ID): Institut Pertanian Bogor.

Lecocq, X., dan B. Demil. 2010. Business model evolution: in search of dynamic consistency. Long Range Planning, 43: 227-246.

Marin JC. 2012. The Impact of Strategic planning and the balanced scorecard methodology on middle manager's performance in the public sector. International $J$ Business and Social Science, 3(1): 114-127.

McGrath RG. 2010. Business models: a discovery driven approach. Long Range Planning, 43: 247-261.

Mulyadi, E., O. Hendriyanto, dan N. Fitriani. 2008. Konservasi Hutan Mangrove Sebagai Ekowisata.Jurnal Ilmiah Teknik Lingkungan, 2(1): 11-18.

Nielsen C, Montemari M. 2012. The role of human resources in business model performance: the case of network-based companies. Forthcoming in J of Human Resource Costing and Accounting, 16(2): 142-164.
Osterwalder, A. dan Y. Pigneur. 2013. Business Model Generation. Ed ke-4. Natalia RS, penerjemah. Jakarta (ID): PT Elex Media Komputindo. Terjemahan dari: Business Model Generation.

Pearce dan Robinson. 2008. Manajemen Strategis: Formulasi, Implementasi dan Pengendalian. Jakarta (ID): Salemba Empat.

Sahut, J. Michel, L. Hikkerova, M. Khalfallah. 2013. Business Model and Performance of Firms. International Business Research, 6(2): 64-76.

Singh T, M.H. Slitkin, A.R. Vamosi. 2007. Attitude towards ecotourism and environmental advocacy: Profiling the dimensions of sustainability. Journal of Vacation Marketing, 13(2): 119-134.

Tjaturpriono. 2010. Business model innovation: menciptakan lanskap bisnis baru. JFMM. 24(4).

Umar, H. 2010. Desain Penelitian Manajemen Strategik: Cara Mudah Meneliti Masalahmasalah Manajemen Strategik untuk Skripsi, Thesis, dan Praktik Bisnis. Jakarta (ID): Rajawali Pers.

Wheelen TL dan J.D. Hunger. 2010. Manajemen Strategis. Julianto A (penerjemah). Yogyakarta, Andi. 